\title{
Maternal-Fetal Simulator
}

\author{
By L.R. Rodrigo', A.M. Marcelo² and A.S. Anderson' \\ ${ }^{1}$ Moinhos de Vento Hospital/ Clinical Engineering, Porto Alegre, Brazil. \\ ${ }^{2}$ Moinhos de Vento Hospital/ Clinical and Hospital Engineering, Porto Alegre, Brazil.
}

\begin{abstract}
This study presents the implementation of a low-cost automated prototype, in an open code platform, that simulates the maternalfetal signal using the Arduino platform. Several options exist for providing a basic evaluation of the maternal-fetal monitors, but the need to simulate the medical environment with a man-machine interface is needed in this age of simulation-based medicine. Another possible application of this simulator is as a teaching tool. Using data generated by the simulator the man-machine interface can measure fetal movement, uterine activity, and fetal heart rate. The data from the interface can then be compared with those presented by the fetal monitor. This comparison makes it possible to check the correct functioning of the equipment tested.

\section{Keywords - Fetal Monitor, Quality Control, Biomedical Simulator, Arduino.}

Copyright (C) 2021. This is an open-access article distributed under the terms of the Creative Commons Attribution License (CC BY): Creative Commons - Attribution 4.0 International - CC BY 4.0. The use, distribution or reproduction in other forums is permitted, provided the original author(s) and the copyright owner(s) are credited and that the original publication in this journal is cited, in accordance with accepted academic practice. No use, distribution or reproduction is permitted which does not comply with these terms.
\end{abstract}

\section{INTRODUCTION}

The concern over fetal cardiac arrhythmia has increased over the last few years, creating a bigger demand in the use of fetal monitoring methods. ${ }^{1}$ The function of the electronic fetal monitor is to detect and record both the heart rate of the fetus and the uterine activity of the mother in labor. ${ }^{2}$ To verify the electronic functioning of the fetal monitor there is a need for performance testing. The tests are divided into two parts - quality evaluation (that consists of visual inspection of the structural conditions of the equipment, parts, modules, and accessories) and quantity tests (that consists of the measurement or simulation of biomedical parameters of the equipment). ${ }^{3}$

An alternative to the test is to use simulators. Simulators aim to present practical situations from everyday life. ${ }^{4}$ The use of simulators also allow new approaches in education and medical practices such as simulation-based medicine.
For example, the students can use anatomical and physiological simulations to predict the results of procedures and, therefore, keep up with the results of treatments in virtual patients. ${ }^{5}$ The improvement of simulators in the health field is largely due to the use and sophistication of Artificial Intelligence-based on microprocessors using algorithms that can change concepts and mechanisms are used. ${ }^{6}$

The Arduino platform is an easy to use micro-processing tool that allows the utilization of medicine-based simulation. Arduino is based on a very versatile system microcontroller that potentate its functions beyond a simple passive interface of data acquisition and can operate independently while controlling many devices. ${ }^{7}$ Due to the need for testing of maternal-fetal monitors, developing a strict quality process allows for the appraisal 
of the level of equipment deterioration. This provides information about deficient components and verifies the quality of repairs made. ${ }^{8}$ In the continuous processes of improvement the implementation of quality control aims to guarantee the safety and reliability of the results of the diagnostic testing. ${ }^{9}$

Another point to consider is the need to involve the assistant medical team in the performance of a hospital's medical technology. Besides understanding the technology used, the assistant team (doctors, nurses etc) will involved increasingly in the life cycle of the equipment. To help with cost reduction and maximize the clinical benefits, interaction with the clinical engineers guarantees the effectiveness of preventive maintenance through the use of simulator-based tests and allow participation in the evaluation of potentially outdated or unsafe technology. ${ }^{10}$ To address this need we developed a low-cost automated system prototype to simulate uterine contractions and fetal heartbeats. The aim was to make it easy to use in universities and hospitals that are looking for quality in fetal monitors testing.

\section{METHOD}

With the specified, calculated, modeled, and simulated data, a prototype was designed, developed, and tested according to the flow-gram demonstrated in Figure $1 .{ }^{1}$

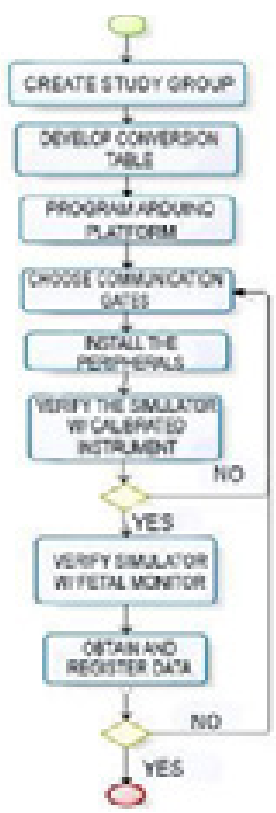

FIGURE 1. Method flow-gram.
Initially, the project was organized as a study group for evaluating the possible solutions for a low-cost prototype of a maternal-fetal simulator. Many follow-ups were made with the nursing team in the obstetric center to measure real antenatal exam. The other steps outlined in the flowgram in Figure 1 are described below in Equation 1 and gram in 1 are described below in Equation 1 an Equation 2 as atwo-step conversion calculation that was within the limits of the processor and the requirements

$$
\begin{array}{ll}
\mathrm{IBPM}=1 / 60 \mathrm{~Hz} & \text { (Equation 1) } \\
\mathrm{T}=1 / \mathrm{f} & \text { (Equation 2) }
\end{array}
$$

Through these calculations Table 1 was created within the parameters of the development of the program. Time periods with whole numbers were used to facilitate the programming.

TABLE 1. Conversion - Relation between Heart Rate (BPM), Frequency $(\mathrm{Hz})$ and Period $(\mathrm{Ms})$

\begin{tabular}{|c|c|c|}
\hline $\mathbf{( B P M})$ & $\mathbf{( H z})$ & Period $(\mathbf{M s})$ \\
\hline 30,0 & 0,5 & 2000,0 \\
\hline 60,0 & 1,0 & 1000,0 \\
\hline 90,0 & 1,5 & 666,7 \\
\hline 120,0 & 2,0 & 500,0 \\
\hline 180,0 & 3,0 & 333,3 \\
\hline 240,0 & 4,0 & 250,0 \\
\hline
\end{tabular}

\section{PROGRAM}

In this step we dealt with programming for the Arduino platform (Figure 2), with the principle of language C. Based on Table 1, the periods of each heartbeat were defined causing each one to stay for a minute. After this step, the signal of fetal movement was programmed with the stimulus of five pulses at intervals of one minute. After that, the lines of programming were implemented for the sensor responsible for controlling the pressure bomb causing a variation of pressure of $0-100 \mathrm{mmHg}$. After getting to maximum pressure, to stabilize the circuit for getting to maxim a minute ata 50 mm pressure or he system. Lastly, the display was programmed to show the pulses of fetal movement, uterine pressure and heart rate/frequency of the fetus.

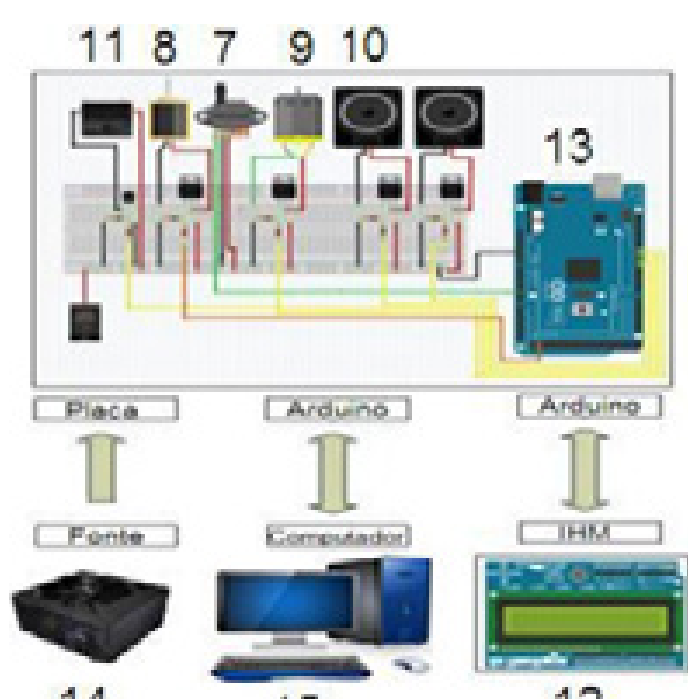

15
IGURE 2. Arduino platform circuit diagram

\section{INSTALLING THE PERIPHERALS}

The system used a selective on/off key. The power to the board and peripherals was through a computer source. For the electromechanical components (the speakerwhich is responsible for the sound wave emission that will stimulate the ultrasonic transducer o the fetal monitor), a TIP122 was used that received power of $12 \mathrm{~V}$ from the switching power supply. Control of simulation of the fetal movement was via the use of a $12 \mathrm{~V}$ relay with a NA contact. The pressure sensor used was an MPX5700DP, which. The which conten neonatal PNI and was connected directly in the sensor was powered by the $12 \mathrm{~V}$ source. The pressure bomb
was connected with the component TIP22 and powered by $12 \mathrm{~V}$ from the switching power supply.

The valve connected to the TIP122 received control of the main board and was also powered by the $12 \mathrm{~V}$ power supply. The display was connected to the processor board. In this prototype the Arduino MEGA microcontroller was used The coding platform and free hardware that has its awn complerwas developed for use by peoplewithlittle rogramming knowledge.

The microcontroller used in the Arduino MEGA 2560 was the ATMEL ATmega2560, an 8-bit microcontroller of advanced RISC architecture. It has $256 \mathrm{~KB}$ of Flash (8 KB more are used for the boot-loader), $8 \mathrm{~KB}$ of RAM and $4 \mathrm{~KB}$ of EEPROM. It has 16 MIPS, operating in $16 \mathrm{MHz}$. Arduino based in Atmel ATMEGA, among which can highlight 4 communication serial channels, 16 analog inputs, and 15 PWM outings. It has SPI communication, $12 \mathrm{C}$ and 6 pins of external interruption. The MEGA 2560 board has 54 input pins and digital outputs that can be used as inputs or outputs. The pins operate with a tension of $5 \mathrm{~V}$ and can provide or drain up to $40 \mathrm{~mA}$. Each pin has a "pull-up" provide or drain up to $40 \mathrm{~mA}$. Each pin has a "pull-up" intern resistor that can be enabled by software. It has 16 analoginputs (A0 to A15 $\mathrm{pins}$, where theconversion can be made with a resolution of $10 \mathrm{bits}$, that is, the value will be converted between 0 and 1023 .

IHIM

The IHM of the Arduino platform was chosen so the simulator could have mobility and easily interface between the operator and the device.

Driver

The TIP122 was used to control the electromechanical devices.

Power Source

Standard 12V, 2.3A, real potency of 500 Watts, Efficiency $>70 \%$, MTBF of 100.000 hours, $25^{\circ} \mathrm{C}$, intern protection against short circuit OVP/OCP/SCP, AC input with manual switching $110 / 220 \mathrm{~V}$, low acoustic noise, cables with protection covering, cooling temperature controller system, silent ventilator of $120 \mathrm{~mm}$, IEC60950 technical norms (electrical safety), IEC 61000 (electromagnetic norms (electrical safety),
safety), on/off switch.

Diaphragm Pump

A diaphragm pump was used to inject pressure on a plastic membrane controlled by the pressure senso which generated pressures to the touch. Figure 3 shows the system functions of the circuit.

Relay - with a NA/NF of $12 \mathrm{~V}$.

Speaker $-4 \Omega / 66 \mathrm{~W}$.

Neonatal Cuff - Cuff of neonatal PNI with a tube.

Valve - Valve with solenoid of $12 \mathrm{~V}$.

Pressure Sensor - MPX5700DP.

TIP122 - 5A, power transducers, 60 volts, 65 watts. 


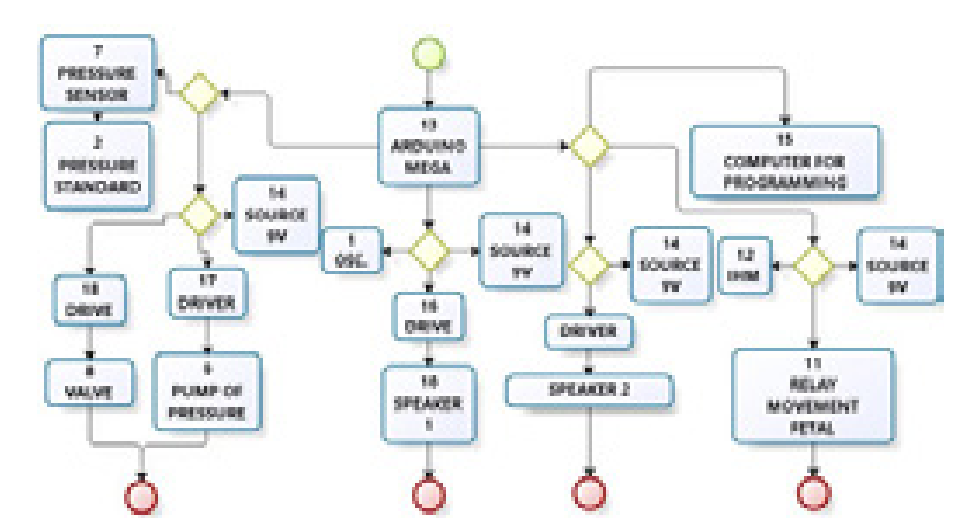

FIGURE 3. Circuit flow-gram.

RESULTS

After connecting all peripherals, the program was run to verify if the simulator was within the minimum of uncertainty. To determine the reliability of the prototype a digital oscilloscope was connected (Figure 4) in the a digital oscilloscope was connected (Figure 4) in the
pressure circuit. The cycle of the program was monitored pressure circuit. The cycle of the program was monitored
through this oscilloscope and calibrated with traceability.

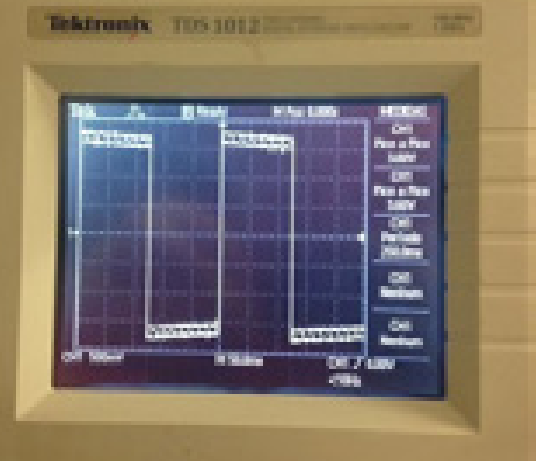

FIGURE 4. Frequency generated by Arduino.

To obtain the final results, the fetal monitor's transducers were connected in the simulator and five tests were executed with satisfactory results as shown in the IHM, with the visualization of the measurement of the fetal movement (Figure 5), uterine activity (Figure 6), and fetal heart rate (Figure 7).

\section{Mov: Fotsel MF: Foter}

FIGURE 5. IHM fetal movement.
Ativ. Uterina

TOCO : $50 \mathrm{~mm}$

FIGURE 6. IHM uterine activity.

Fres. Gand.Fetal

BPH 120

FIGURE 7. IHM fetal heart rate.

As a complement to the results, Figure 8 shows the system during the testing of the prototype including the number identification for the components of the system. This is also shown in Figure 8.

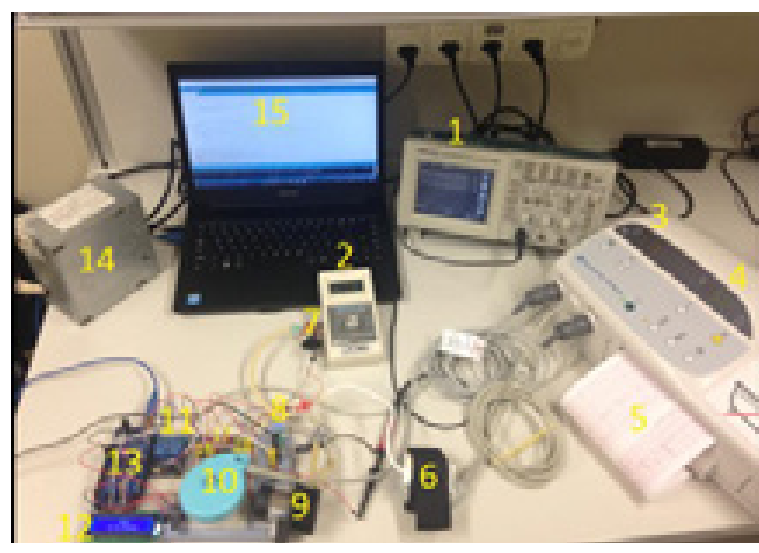

FIGURE 8. Prototype test.

\section{DISCUSSION}

It wasn't simple to reproduce the BPM with an electromechanical system and develop a structure that accon modates the sensor of prow-cost prototype. One of the difficulties was transforming the "electronic garbage" (useless components) available in to the appropriate components needed in the simulator. One of the improvements to the project could be a WiFi-connected system to allow Cloud storage of data and information collected by the fetal detectors. The data could be identified as patrimony or by an identification code.

Proposed future improvement requiring further study include the development of similar devices to analyze
PNI, ECG, and electrical tests, in an integrated way by adding modules to this simulator. This would be made easier due to the simplicity of the program structure and that the Arduino platform has many tutorials available on the Internet.

\section{CONCLUSION}

The goal of simulating uterine contractions and fetal heart rate with a low-cost automated system was accomplished using quality standards in the tests of the maternalfetal monitors and executed by the clinical engineering services. Additional improvements, developments, and new validations are also achievable.

\section{CONFLICT OF INTEREST}

The authors declare that they have no conflict of interest.

\section{REFERENCES}

1. Lindsey AD, Robert HA, Sullivan ID, et al. Evaluation of fetal arrhythmias by echocardiography. Br Heart J 1983.

2. Zielinsky P. Arritmias cardíacas fetais: papel da ecocardiografiapré-natal no diagnóstico e na terapêutica intrauterina. In: Cruz FES, Maia IG. Eletrofisiologia Clínica e Intervencionista das Arritmias Cardíacas. Rio de Janeiro: Ed. Rev. Interna 1997;31723.
3. Lucatelli MV, Batista MB, Silva HP, Garcia R. Metrologia para a Vida Sociedade Brasileira de Metrologia (SBM) Setembro 2003;01-05.

4. Dias CF, Rosecler MB, Mussoi RB. Revista Brasileira de Informática na Educação 2014;22(2).

5. Villamil MB. Modelagem e Simulação da Articulação Temporomandibular. Universidade Federal do Rio Grande do Sul. Instituto de Informática. Programa de Pós-GraduaçãoemComputação; 2009.

6. Almeida MC, Tavolaro CR, Molisani E. Rev. Bras. Ensino Fís.Vol.3n.4.São Paulo 2011;Oct./Dec.

7. Souza AR, Paixão AC, Uzêda DD, et al. A placa Arduino: uma opção de baixo custo para experiências de física assistidas pelo PC. Revista Brasileira de Ensino de Física 2011;33(1)1702.

8. Oliveira LM, Maia JM, Gamba HR, et al. Avaliação da qualidade de imagens de equipamentos de ultrassom modo-B. Revista Brasileira de Engenharia Biomédica 2010;26(1):11-24.

9. Severo LS, Lammoglia RS, Saito RH, et al. Aplicação dos Testes de Verificação dos Indicadores da Qualidade de Equipamentos de Ultra-sonografia. Instituto de Eletrotécnica e Energia da USP 2001.

10.Ministério da Saúde. Avaliação tecnológica em saúde: subsidiando a melhoria da qualidade e eficiência do SUS (Reforsus). Brasília (DF): Ministério da Saúde; 1998. 